\title{
Fontes de Stress Ocupacional em Professores do Ensino Básico e Médio em Moçambique, Brasil e Portugal: uma Revisão Sistemática de Literatura
}

\author{
Gildo Aliante ${ }^{1}$ \\ Mussa Abacar ${ }^{2}$ \\ ${ }^{1}$ Instituto de Psicologia da Universidade Federal do Rio Grande do Sul, Brasil; E-Mail: aliantegildo@yahoo.com.br \\ ${ }^{2}$ Universidade Federal de Pernambuco, Brasil; E-Mail: abacarmussa@yahoo.com.br
}

\begin{abstract}
Resumo
O professor desempenha um papel crucial na implementação das políticas públicas educativas (currículos, objectivos, metas educacionais). Ainda assim, este é frequentemente sujeito a trabalhar em situações precarizadas e nocivas à sua saúde mental, física e psicológica, o que leva a ocorrência de stress ocupacional e ao esgotamento profissional. Vários estudos têm sido realizados em diferentes contextos para identificar os potenciais preditores do stress no trabalho docente. Este artigo de revisão de literatura visa identificar as fontes de stress ocupacional em professores do ensino básico e médio em Moçambique, no Brasil e em Portugal. Foram analisados 28 estudos que abordam as fontes de stress ocupacional em professores do nível básico e médio, sendo 18 estudos realizados no Brasil, 5 em Moçambique e igual número em Portugal. Os resultados indicam que o stress ocupacional é um problema que afecta os professores nos três países, sendo as causas comuns e mais apontadas nos estudos analisados as seguintes: sobrecarga de trabalho, indisciplina e mau comportamento de alunos, maior número de alunos/sala, desinteresse pela aprendizagem e desmotivação de alunos, seguidos de salários e remunerações baixos, condições precárias e inadequadas de trabalho docente, e relacionamento com os pais e família dos alunos. Estas situações implicam um repensar sobre o ensino nos países estudados, o que sugere que este deve ser um trabalho ergonomicamente desenhado, o que pressupõe a aplicação de teorias, modelos, leis e dos métodos da ergonomia no contexto educativo.
\end{abstract}

Palavras-chave: ensino básico e médio; professor; stress ocupacional; trabalho docente.

\begin{abstract}
The teacher plays a crucial role in the implementation of public educational policies (curricula, objectives, educational goals). Even so, he is often subject to work in precarious situations and harmful to his mental, physical and psychological health, which leads to the occurrence of occupational stress and to professional exhaustion. Several studies have been carried out in different contexts to identify the potential predictors of stress in the teaching work. This literature review article aims to identify the sources of occupational stress in primary and secondary school teachers in Mozambique, Brazil and Portugal. We analyzed 28 studies that address the sources of occupational stress in elementary and middle school teachers, with 18 studies in Brazil, 5 in Mozambique and the same number in Portugal. The results indicate that occupational stress is a problem that affects teachers in the three countries. The most common causes are: work overload, indiscipline and misbehavior among students, greater number of students / room, lack of interest By the learning and demotivation of students, followed by low wages and salaries, precarious and inadequate conditions of teaching work, and relationships with parents and students' families. These situations imply a rethinking of teaching in the countries studied, which suggests that this should be an ergonomically designed work, which presupposes the application of theories, models, laws and methods of ergonomics in the educational context.
\end{abstract}

Keywords: primary and secondary education; teacher; teaching work; occupational stress. 


\section{Introdução}

O trabalho humano constitui um factor fundamental para o ser humano, pois além de permitir integração na sociedade em sociedade, é um meio de subsistência, sobrevivência e realização pessoal. Assim, o trabalho é uma das fontes de satisfação de diversas necessidades humanas, como auto-realização, manutenção de relações interpessoais e sobrevivência (Murta \& Tróccoli, 2004). Todavia, na sociedade contemporânea, o trabalho humano tem sido afectado por diversas transformações tais como: flexibilização, desregulação, precarização (Silva, 2014).

Ora, essas mudanças decorridas na sociedade contemporânea têm atingido sem precedentes o trabalho docente. Assim, salienta-se que as modificações sociopolíticas e econômicas intensificadas a partir da década de 1990 para cá produziram diversas mudanças no âmbito do trabalho docente (Santos et al., 2016). Por conseguinte, os docentes passam a conviver com um ambiente precarizado, regido pela lógica empresarial, levando a situações de sobrecarga, de stress e de competição, além de fragilizar as relações interpessoais e dificultar o uso adequado do tempo livre, aspetos esses que comprometem a qualidade de vida dos docentes.

Entende-se que o trabalho humano quando executado subcondições insalubres ou inseguras tem efeito direto sobre o bem-estar físico e psíquico do homem (...) (Ladeira, 1996). Na verdade qualquer trabalho executado em situações desumanas pode originar a ocorrência de várias doenças ocupacionais, como o stress ocupacional e o burnout. Estudos revelam que a docência afigura-se como uma das profissões potencialmente stressantes devido a presença de diversos stressores psicossociais associados ao trabalho.

Este trabalho visa mapear as fontes de stress ocupacional em professores do ensino básico e médio em três países falantes de língua portuguesa: Moçambique, Brasil e Portugal. É estudo que resulta da revisão da literatura, e envolveu a análise de artigos científicos, dissertações e teses obtidos publicados sobre ao stress do professor nos níveis analisados.

O mapeamento das fontes de stress apresentado nesta pesquisa permite visualizar os preditores do stress ocupacional na carreira docência no ensino básico e médio, o que pode ajudar os gestores educacionais e fazedores de políticas públicas educativas a melhorar as situações de trabalho que contribuem para a ocorrência do stress do professor. A identificação dos fatores que causam o stress ocupacional pode contribuir para a elaboração de propostas de promoção de saúde no ambiente de trabalho (Silva \& Silva, 2015). E assim, estaríamos contribuindo para a melhoria da qualidade de vida dos professores, uma vez que a compreensão do stress ocupacional é de capital importância na redução do stress negativo no trabalho que está associado com o stress na organização.

\section{Marco Teórico}

Para melhor compreensão do stress no trabalho é necessário entender alguns conceitos. Nesta parte do artigo é apresentada a conceituação dos termos stress e stress ocupacional. Posteriormente são apresentados os factores do stress ocupacional no contexto organizacional.

\subsection{Conceptualização do Stress e Stress Ocupacional}

O termo stress tem recebido diferentes conotações no seio de literatura científica. Todavia, muitos dos conceitos convergem com o concebido por Seyle, considerado como pioneiro no estudo do assunto. Seyle (1956) define stress como o estado manifestado por uma síndrome específica, constituída por todas as alterações não específicas produzidas num sistema biológico.

Para Seyle o stress pode ser visto sob duas perspectivas: stress positivo (eustress) e stress negativo (distress). Os termos eustress e distress são associados tanto ao stress enquanto processo quanto ao stress resultado de um processo (Marras \& Veloso, 2012). Enquanto processo a diferença entre eustress e distress, distingue-se pelos eventos de natureza positiva ou de natureza negativa respectivamente. Enfim, o eustress é o que tem consequências positivas e gera resistência nos indivíduos e o distress é o stress negativo, que gera vulnerabilidade e enfraquece o indivíduo. No contexto deste trabalho, consideramos tratamos o stress como sinónimo de distress.

O stress ocupacional é o processo de perturbação engendrado no indivíduo pela mobilização excessiva da sua energia de adaptação, para o enfrentamento das solicitações do seu ambiente profissional, solicitações estas que ultrapassam 
as capacidades actuais, físicas e/ou psíquicas do indivíduo (Marras \& Veloso, 2012). Numa outra acepção o stress compreende todas as reações biológicas e psicológicas de um indivíduo e de acções humanas delas decorrentes para lidar com um agente stressor, sendo que este pode se configurar como ameaça real, percebida e/ ou socialmente construída. Assim, o stress ocupacional ou profissional configura- -se quando a origem dos agentes stressores é eminentemente proveniente do espaço do trabalho ou decorrente das actividades realizadas naquele ambiente, ou seja, é aquele cuja causa é inerente ao trabalho que o sujeito executa.

Nesse contexto, o stress ocupacional do professor é definido segundo Kyriacou (2001), como as experiências desagradáveis de um professor traduzidas em emoções negativas como a raiva, a frustração, a ansiedade, a depressão e o nervosismo, resultante de algum aspecto de seu trabalho e mediadas pela percepção de que as exigências profissionais constituem uma ameaça à sua auto-estima ou bem-estar. Com efeito, um professor stressado é aquele que percebe que necessita de mais recursos do que aqueles que dispõe para enfrentar uma determinada tarefa ou missão que lhe é incumbida. Neste estudo, o stress ocupacional do professor é entendido como sendo um tipo de stress cuja causa primordial é proveniente do ambiente de trabalho docente.

\subsection{Fases do Stress}

O modelo trifásico de evolução do stress, proposto por Hans Selye, a chamada "Síndrome Geral de Adaptação", compreende três fases: fase de alarme, fase de resistência e fase de exaustão (Robins, 2005, 2009; Daft, 2005). Porém, ao validar o Inventário de Sintomas de Stress para Adulto de Lipp (ISSL), identificou, tanto clínica como estatisticamente, uma quarta fase, a qual denominou de quase- -exaustão, por se encontrar entre as fases de resistência e exaustão (Júnior \& Lipp, 2008).

Fase de alerta - a primeira do processo do stress, constitui a fase positiva do stress. Quando a pessoa se confronta inicialmente com um estressor, uma reacção de alerta se instala e o organismo se prepara e nota-se a consequente quebra da homeostase. O estressor tem uma duração curta, a adrenalina é eliminada e ocorre a restauração da homeostase e a pessoa sai dessa fase sem complicações para o seu bem-estar. É nesta fase que acontece um aumento na produtividade e, se a pessoa sabe administrar o stress, ela pode utilizá-lo em seu benefício devido à motivação, entusiasmo e energia que a mesma produz (Lipp et al., 2004; Júnior \& Lipp, 2008). Tal fase pode ser caraterizada pela produção e ação da adrenalina, que torna a pessoa mais atenta, mais forte e mais motivada. Os sintomas característicos nesta fase são: aumento da frequência respiratória, dilatação dos brônquios e da pupila, além de contracção do baço e aumento do número de linfócitos na corrente sanguínea, para reparar possíveis danos ao organismo. Percebemos as reacções de tensão muscular, mãos frias e suadas, sensação de nó no estômago e aumento da transpiração (Júnior \& Lipp, 2008).

Fase de resistência - ocorre se a fase de alerta for mantida, ou seja, se o stressor perdura ou se ele é de longa duração e intensidade excessiva, porém não prejudicial ao organismo. Por meio de sua ação reparadora o organismo tenta restabelecer a homeostase. Quando consegue, os sintomas iniciais desaparecem e a pessoa tem a impressão de que está melhor. Quando não consegue, a produtividade sofre uma queda dramática e a vulnerabilidade da pessoa aumenta. Nessa fase, o organismo utiliza toda a energia adaptativa para se re-equilibrar. No entanto, se essa reserva é suficiente, a pessoa consegue equilibrar-se e sai do processo do stress. Se o stressor exige mais esforço de adaptação, além da capacidade do indivíduo, o organismo se enfraquece tornando-se vulnerável às doenças, porém se o stressor é eliminado a pessoa poderá voltar ao estado normal, sem sequelas. A pessoa em estado de stress poderá passar do estado de alerta para o de resistência em questão de segundos. São dois os sintomas que aparecem de modo bastante frequente nesta fase: a sensação de desgaste generalizado sem causa aparente e dificuldade com a memória. No nível psicológico, muitas mudanças podem ocorrer principalmente em termos do funcionamento das glândulas supra- renais: a medula diminui a sua produção de adrenalina e seu córtex produz corticosteróides. Várias doenças já começam a surgir nesta fase, dentre elas, picos de hipertensão, herpes simples e psoríase e até o diabetes nas pessoas geneticamente predispostas a ele (Júnior \& Lipp, 2008).

Fase de quase-exaustão - ocorre quando a tensão excede o limite do gerenciável e a resistência física e emocional começa a se quebrar. Existem, ainda, momentos em que a pessoa consegue pensar lucidamente, tomar decisões, rir de piadas e trabalhar, porém, tudo isso é feito com esforço, e esses momentos de funcionamento normal se intercalam com momentos de total desconforto. É uma fase caraterizada por muita ansiedade. As doenças que surgem na fase de resistência tendem a aumentar (Op. cit). 
Fase de exaustão - é a fase considerada como a mais negativa do stress. É patológica e ocorre quando o stressor perdura por mais tempo ou quando outros stressores ocorrem, simultaneamente, evoluindo o processo de stress. Nesse percurso, instala-se a exaustão psicológica, em forma de depressão. A exaustão física se manifesta e as doenças aumentam, inclusive doenças graves. É caracterizada pelo aparecimento dos sintomas da primeira fase, além de outros tais como: insónia, problemas dermatológicos, estomacais, cardiovasculares, instabilidade emocional, apatia sexual, ansiedade aguda, inabilidade de tomar decisões, vontade de fugir de tudo, autodúvida, irritabilidade. Na área física, caracteriza-se com a presença de hipertensão arterial, úlceras gástricas, retracção de gengivas, psoríase, vitiligo e até diabetes. Em alguns casos, poderá ocorrer, inclusive, a morte (Ibid.).

\subsection{Fontes de Stress Ocupacional}

São várias as fontes de stress ou agentes stressores. Um agente stressor é um elemento, facto, situação, contexto real e/ou percebido que se configura para o indivíduo como uma exigência de resposta por ser entendida, consciente ou não consciente, como ameaçadora (Marras \& Veloso, 2012).

$\mathrm{O}$ stress pode ser causado por factores biológicos e psicossociais. Ainda assim, neste artigo apresentamos as fontes de stress ocupacional de acordo com a acepção de que o stress ocupacional como aquele que é causado por um agente de stress relacionado com ambiente de trabalho (factores psicossociais).

Maslach e Leite (1999), defendem que as causas de esgotamento físico e emocional localizam-se mais no ambiente do trabalho do que no indivíduo. Partindo desse pressuposto, estes autores dividem as causas em: excesso de trabalho, falta de controle do trabalho, remuneração insuficiente, colapso da união, ausência de equidade no local de trabalho e valores conflituantes entre o trabalhador e a organização.

Já o modelo teórico de Cooper, Sloan e Willians (1988) concebem as fontes de stress em cinco grupos básicos: factores intrínsecos ao trabalho; papel na organização, o relacionamento interpessoal, carreira/realização e clima/estrutura organizacional e a interface trabalho/família.

- Factores intrínsecos ao trabalho: condições de trabalho (barulho, calor, ritmo de produção, configuração do trabalho em turnos, riscos e perigos); sobrecarga quantitativa e qualitativa, modificações de tecnologia (Marras \& Veloso, 2012).

- Papel da organização: ambiguidade e conflito de papéis, responsabilidades envolvidas;

- Relacionamento interpessoal: com chefes, entre colegas. No âmbito educacional podem se dizer que, as relações interpessoais ruins entre professor-gestores escolares, professor-aluno, professor-pais e encarregados de educação e entre professores podem constituir uma fonte de stress.

- Carreira e realização: a falta de segurança profissional, o medo da obsolescência ou da aposentadoria, divergência de capacidade individuais e tarefa, impossibilidade de desenvolvimento de carreira, o medo de perder emprego, avaliação de desempenho podem constituir agentes stressores nos indivíduos;

- Clima e estrutura organizacional: falta de autonomia, de iniciativa e liberdade, falta de participação no processo decisório.

- Conflito trabalho-familia: interferência negativa do trabalho na vida familiar e vice-versa.

As causas de stress ocupacional são numerosas e variadas. E a docência afigura- se como uma das profissões mais stressantes na actualidade, devido a presença de vários stressores no ambiente de trabalho (Carvalho \& Roazzi, 2011).

\section{Metodologia}

Para a realização deste estudo exploratório recorreu-se a revisão de artigos científicos, dissertações e teses obtidos nos sites académicos disponíveis na internet, para além da consulta de livros. Foram analisados um total de 28 estudos sobre stress ocupacional em professores do nível básico e médio, sendo 18 estudos realizados no Brasil, 5 em Moçambique e igual número em Portugal. 


\subsection{Procedimento}

Inicialmente, foram feitas buscas na internet em diversas revistas científicas a partir de descritores: burnout em professores, esgotamento profissional em professores, stress ocupacional em professores, trabalho docente e malestar docente. Em seguida foram selecionados os artigos que melhor se enquadravam com o objectivo definido, ou seja, aqueles em que possibilitassem identificar as fontes ou causas do stress ocupacional em professores do ensino básico ou secundário nos três países: Moçambique, Brasil e Portugal. Foram consideradas as fontes que apareceram com maior frequência nos estudos analisados.

\section{Análise e Discussão de Resultados}

Esta parte é dedicada a análise e discussão dos resultados achados a partir da pesquisa bibliográfica sobre fontes de stress em professores de três países da CPLP (Comunidade dos Países de Língua Portuguesa) a saber: Moçambique, Brasil e Portugal. Para além do critério de língua portuguesa que ambos os países são falantes, a escolha dos mesmos deveu-se pela disponibilidade de pesquisas realizadas em ambos os países. Na Tabela 1 são apresentadas as fontes de stress ocupacional em professores nos três países em estudo. Os estudos foram catalogados de acordo com o nome do autor e ano de publicação, país e resultados encontrados pelos autores.

Tabela 1. Fontes de stress ocupacional em professores (Moçambique, Brasil e Portugal)

\begin{tabular}{|c|c|c|}
\hline Autor(es) & País de estudo & Resultados \\
\hline $\begin{array}{c}\text { Comité de } \\
\text { Conselheiros } \\
(2003)\end{array}$ & Moçambique & $\begin{array}{l}\text { - Insuficiente qualificação pedagógica dos professores; } \\
\text { - Condições difíceis e precárias em que trabalham os professores; } \\
\text { - Pouco apoio em termos pedagógicos; } \\
\text { - Baixos salários e atrasos no pagamento de salários; } \\
\text { - Falta de motivação por parte dos professores que abraçaram a carreira como } \\
\text { um emprego de recurso à espera de um outro melhor; } \\
\text { - Falta de reconhecimento e incentivos aos professores mais dedicados; } \\
\text { - Falta de reciclagem periódica }\end{array}$ \\
\hline Abacar (2011) & Moçambique & $\begin{array}{l}\text { - Salário, } \\
\text { - Benefícios, } \\
\text { - Relacionamento com os pais e encarregados de educação, } \\
\text { - Desenvolvimento de carreira, } \\
\text { - Sobrecarga de trabalho, } \\
\text { - Pressão de tempo e, } \\
\text { - Recursos materiais e físicos. }\end{array}$ \\
\hline Abacar (2015) & Moçambique & $\begin{array}{l}\text { - Baixos Salário e falta de benefícios, } \\
\text { - Condições de trabalho, } \\
\text { - Comportamento dos alunos, } \\
\text { - Aprendizagem dos alunos, } \\
\text { - Desvalorização docente, } \\
\text { - Sobrecarga de trabalho, } \\
\text { - Relações interpessoais, } \\
\text { - Desenvolvimento de carreira, } \\
\text { - Participação de pais e encarregados de educação. }\end{array}$ \\
\hline $\begin{array}{c}\text { Abacar e } \\
\text { Amade (2016) }\end{array}$ & Moçambique & $\begin{array}{l}\text { - Condições de trabalho, } \\
\text { - Clima organizacional, } \\
\text { - Características do trabalho, } \\
\text { - Desenvolvimento na carreira. }\end{array}$ \\
\hline $\begin{array}{c}\text { Abacar e Aliante } \\
\qquad(2016)\end{array}$ & Moçambique & $\begin{array}{l}\text { - Baixo salário, } \\
\text { - Fraco rendimento acadêmico dos alunos, } \\
\text { - Falta dos alunos às aulas, } \\
\text { - Falta de concentração dos alunos às orientações para as tarefas, } \\
\text { - Mau comportamento dos alunos, ou seja, ter alunos que conversam e/ou } \\
\text { brincam o tempo todo. }\end{array}$ \\
\hline Naujorks (2002) & Brasil & $\begin{array}{l}\text { - A falta de preparo dos professores para o processo de inclusão, } \\
\text { - Inexistência de projetos de educação continuada que os capacite para } \\
\text { enfrentar a "nova" demanda educacional, } \\
\text { - Elevado número de alunos por turmas, }\end{array}$ \\
\hline
\end{tabular}




\begin{tabular}{|c|c|c|}
\hline & & $\begin{array}{l}\text { - Infra-estrutura física inadequada; } \\
\text { - Falta de trabalhos pedagógicos em equipe, } \\
\text { - Desinteresse da família em acompanhar a trajetória escolar de seus filhos, } \\
\text { - Indisciplina cada vez maior, } \\
\text { - Desvalorização profissional, } \\
\text { - Baixos salários. }\end{array}$ \\
\hline $\begin{array}{l}\text { Benevides-Pereira } \\
\text { et al. (2003) }\end{array}$ & Brasil & $\begin{array}{l}\text { - Baixos salários, } \\
\text { - Escassos recursos materiais e didáticos, } \\
\text { - Classes superlotadas, } \\
\text { - Tensão na relação com alunos, } \\
\text { - Excesso de carga horária, } \\
\text { - Inexpressiva participação nas políticas e no planejamento institucional. }\end{array}$ \\
\hline $\begin{array}{c}\text { Oiticica e } \\
\text { Gomes (2004) }\end{array}$ & Brasil & $\begin{array}{l}\text { - Salário não digno, } \\
\text { - Precariedade das condições de trabalho, } \\
\text { - Alto volume de atribuições burocráticas, } \\
\text { - Elevado número de turmas assumidas e de alunos por sala, } \\
\text { - Mau comportamento dos alunos, } \\
\text { - Treinamento inadequado do professor diante das novas situações e } \\
\text { emergências da época. }\end{array}$ \\
\hline $\begin{array}{c}\text { Gasparini; } \\
\text { Barreto e } \\
\text { Assunção (2005) }\end{array}$ & Brasil & $\begin{array}{l}\text { - Violência, } \\
\text { - Piores condições ambientais, } \\
\text { - Ambiente físico e conforto no trabalho, } \\
\text { - Margem de autonomia, de criatividade e } \\
\text { - Tempo no preparo das aulas. }\end{array}$ \\
\hline $\begin{array}{c}\text { Carlotto e } \\
\text { Palazzo (2006) }\end{array}$ & Brasil & $\begin{array}{l}\text { - Carga horária, } \\
\text { - Quantidade de alunos atendidos, } \\
\text { - Mau comportamento dos alunos, } \\
\text { - Expectativas familiares e } \\
\text { - Pouca participação nas decisões institucionais. }\end{array}$ \\
\hline Bastos (2009) & Brasil & $\begin{array}{l}\text { - Sobrecarga de trabalho, } \\
\text { Condições de trabalho existentes na escola: } \\
\text { - Dupla jornada, } \\
\text { - Baixos salários, } \\
\text { - Intensificação das funções e das atividades docentes, } \\
\text { - Novas formas de regulação do trabalho escolar, } \\
\text { - Avaliação sistêmica do desempenho dos alunos. } \\
\text { - Mudanças no processo ensino-aprendizagem causadas pelo fim da seriação e } \\
\text { a introdução dos ciclos de aprendizagem, } \\
\text { - Aumento do número de alunos por sala e } \\
\text { - O novo perfil sociocultural dos alunos, } \\
\text { - Ausência de efetiva participação da família na escolaridade dos filhos, • } \\
\text { Dificuldades de relacionamento interpessoal na escola, } \\
\text { - Problemas na gestão escolar. }\end{array}$ \\
\hline $\begin{array}{l}\text { Branquinho } \\
\text { (2010) }\end{array}$ & Brasil & $\begin{array}{l}\text { - Relações socioprofissionais com alunos e pais dos alunos, } \\
\text { - Falta de reconhecimento no trabalho, } \\
\text { - Cobranças no trabalho, } \\
\text { - Insuficiência de recursos e apoio institucional, } \\
\text { - Indisciplina dos alunos, } \\
\text { - Falta de compromisso dos pais. }\end{array}$ \\
\hline Cruz (2011) & Brasil & $\begin{array}{l}\text { - Muitas responsabilidades, } \\
\text { - Baixa remuneração, } \\
\text { - Ambiguidades de papéis, } \\
\text { - Infraestrutura precária, } \\
\text { - Falta de materiais pedagógicos, } \\
\text { - Falta de qualificação profissional. }\end{array}$ \\
\hline $\begin{array}{c}\text { Santos e } \\
\text { Sobrinho (2011) }\end{array}$ & Brasil & $\begin{array}{l}\text { - Carga horária em sala de aula, } \\
\text { - Número de alunos por sala. }\end{array}$ \\
\hline $\begin{array}{c}\text { Monteiro e } \\
\text { Dalagasperina } \\
\text { (2012) }\end{array}$ & Brasil & $\begin{array}{l}\text { - Excesso de atividades, } \\
\text { - Falta de interesse ou desmotivação dos alunos, } \\
\text { - Falta de educação ou limites dos alunos, } \\
\text { - Baixa remuneração e os prazos estabelecidos para executar as atividades, }\end{array}$ \\
\hline
\end{tabular}




\begin{tabular}{|c|c|c|}
\hline & & $\begin{array}{l}\text { - Atividades extraclasse: a preparação de aulas e de provas, as correções de } \\
\text { provas, a elaboração de pareceres e relatórios os atendimentos on-line e o } \\
\text { preenchimento de cadernos de chamada. }\end{array}$ \\
\hline $\begin{array}{l}\text { Zille e } \\
\text { Cremonezi } \\
\text { (2013) }\end{array}$ & Brasil & $\begin{array}{l}\text { - Conviver com a indisciplina dos alunos, } \\
\text { - Baixo nível de remuneração percebida, } \\
\text { - Levar a vida muito corrida em função do trabalho, } \\
\text { - Trabalhar aos sábados, } \\
\text { - Ter pouco tempo livre para as questões pessoais e } \\
\text { - Realizar várias atividades ao mesmo tempo com alto nível de cobrança. }\end{array}$ \\
\hline $\begin{array}{l}\text { Costa \& Rocha } \\
\qquad(2013)\end{array}$ & Brasil & $\begin{array}{l}\text { - Falta de interesse e a indisciplina dos alunos; } \\
\text { - Falta de estrutura; } \\
\text { - Falta de diálogo e o autoritarismo tanto da coordenação quanto da direção da } \\
\text { escola; } \\
\text { - Individualismo por parte de alguns professores e } \\
\text { - Baixos salários. }\end{array}$ \\
\hline $\begin{array}{c}\text { Silveira; } \\
\text { Enumo e } \\
\text { Batista (2014) }\end{array}$ & Brasil & $\begin{array}{l}\text { - Pouco acompanhamento familiar } \\
\text { - Problemas motivacionais e comportamentais dos alunos }\end{array}$ \\
\hline $\begin{array}{c}\text { Diehl \& } \\
\text { Carlotto (2014) }\end{array}$ & Brasil & $\begin{array}{l}\text { - Indisciplina dos alunos, } \\
\text { - Falta de apoio dos pais e da direção da escola, } \\
\text { - Sobrecarga de trabalho e } \\
\text { - Cobrança social. } \\
\text { - Políticas educacionais ineficazes. }\end{array}$ \\
\hline Ribeiro (2015) & Brasil & $\begin{array}{l}\text { - Indisciplina dos alunos, } \\
\text { - Falta de atenção aos alunos disciplinados. }\end{array}$ \\
\hline $\begin{array}{l}\text { Stachiw, } \\
\text { Ferreira e } \\
\text { Batista (2015) }\end{array}$ & Brasil & $\begin{array}{l}\text { Levar a vida muito corrida em função do trabalho, ter pouco tempo livre para as } \\
\text { questões pessoais e realizar várias atividades ao mesmo tempo. }\end{array}$ \\
\hline $\begin{array}{c}\text { Weber et al. } \\
(2015)\end{array}$ & Brasil & - Disciplina e motivação dos alunos. \\
\hline $\begin{array}{l}\text { Koga et al. } \\
\text { (2015) }\end{array}$ & Brasil & $\begin{array}{l}\text { - Ajustes e relacionamento ruim com alunos, } \\
\text { - Tempo insuficiente para família/lazer, } \\
\text { - Relacionamento ruim com pais, } \\
\text { - Violência física, } \\
\text { - Quantidade de alunos, } \\
\text { - Infraestrutura ruim da escola, } \\
\text { - Oportunidade ruim para expressar opiniões no trabalho. }\end{array}$ \\
\hline Gomes (2003) & Portugal & $\begin{array}{l}\text { - Classes cheias, } \\
\text { - Indisciplina dos alunos, } \\
\text { - Desinteresse dos educandos pelas matérias. }\end{array}$ \\
\hline $\begin{array}{c}\text { Capelo e } \\
\text { Pocinho (2009) }\end{array}$ & Portugal & $\begin{array}{l}\text { - Comportamentos inadequados e a indisciplina dos alunos, } \\
\text { - Pressões de tempo, } \\
\text { - Excesso de trabalho. }\end{array}$ \\
\hline $\begin{array}{c}\text { Correia, } \\
\text { Gomes e } \\
\text { Moreira }(2010) \\
\end{array}$ & Portugal & $\begin{array}{l}\text { - Problemas de disciplina dos alunos, } \\
\text { - Percepção de ineficácia das sanções disciplinares. }\end{array}$ \\
\hline $\begin{array}{l}\text { Gomes et al } \\
\quad(2010)\end{array}$ & Portugal & $\begin{array}{l}\text { - Vínculos profissionais mais precários, } \\
\text { - Maior carga horária de trabalho, } \\
\text { - Mais alunos em sala de aula. }\end{array}$ \\
\hline $\begin{array}{l}\text { Gomes, Peixoto, } \\
\text { Pacheco e Silva } \\
(2012)\end{array}$ & Portugal & $\begin{array}{l}\text { - Pressões de tempo, } \\
\text { - Excesso de trabalho, } \\
\text { - Trabalho burocrático e administrativo. }\end{array}$ \\
\hline
\end{tabular}

Com base na análise do quadro 1, algumas fontes de stress afectam os professores dos três pais estudados. Na Tabela 2 é apresentada a categorização dessas fontes e sua distribuição, em termos percentuais, por cada país (Moçambique, Brasil e Portugal). Assim, o factor condições de trabalho inclui escassez de recursos e materiais físicos, instalações precárias. Enquanto a categoria de relacionamento com pais foi resultado de fusão dos factores falta de participação dos pais na educação dos educandos, relações ruins com pais e exigência dos mesmos. A categoria mau comportamento inclui os factores indisciplina dos alunos, relacionamento ruim com alunos, ajuste de contas, agressões dos mesmos, conversar na aula. 
Tabela 2. Stressores mais regulares na actividade docente em cada país

\begin{tabular}{|c|c|c|c|c|c|c|c|}
\hline \multirow{2}{*}{ Factor stressor } & \multicolumn{2}{|c|}{ Moçambique } & \multicolumn{2}{|c|}{ Brasil } & \multicolumn{2}{c|}{ Portugal } & \multicolumn{1}{c|}{$\begin{array}{c}\text { \% } \\
\text { Total }\end{array}$} \\
\cline { 2 - 7 } & $\mathbf{N}$ & $\mathbf{\%}$ & $\mathbf{N}$ & $\mathbf{\%}$ & $\mathbf{N}$ & 60 & 68.9 \\
\hline Sobrecarga de trabalho & 5 & 80 & 18 & 66.7 & 5 & 60 & 53.3 \\
\hline Mau comportamento de alunos & 5 & 20 & 18 & 80 & 5 & 60 \\
\hline Salários e remunerações baixos & 5 & 80 & 18 & 50 & 5 & - & 43.3 \\
\hline $\begin{array}{c}\text { Condições precárias e inadequadas de } \\
\text { trabalho }\end{array}$ & 5 & 80 & 18 & 50 & 5 & - & 43.3 \\
\hline Maior número de alunos/sala & 5 & 40 & 18 & 27.8 & 5 & 40 & 35.8 \\
\hline $\begin{array}{c}\text { Desinteresse pela aprendizagem e } \\
\text { desmotivação de alunos }\end{array}$ & 5 & 40 & 18 & 22.2 & 5 & 20 & 27.4 \\
\hline $\begin{array}{c}\text { Relacionamento com os pais e } \\
\text { família dos alunos }\end{array}$ & 5 & 40 & 18 & 50 & 5 & - & 30 \\
\hline
\end{tabular}

$\mathrm{n}$ - número de estudos em cada país

$\%$ - frequência percentual de cada factor stressor.

De acordo com a Tabela 2, para Moçambique, a sobrecarga no trabalho, salários e remunerações baixas, condições precárias e inadequadas de trabalho foram os mais apontados nos 5 estudos, seguidos de maior número de alunos por turma, desinteresse e desmotivação dos alunos pela aprendizagem, relacionamento com os pais. Na realidade Brasileira o mau comportamento de alunos foi o mais apontado, seguido de sobrecarga no trabalho, salários baixos, condições inadequadas de trabalho e relacionamento. Por sua vez, em Portugal os factores sobrecarga no trabalho, indisciplinas foram os referenciados seguido de maior número de alunos por turma.

Do modo geral a Tabela 2 ilustra que, em ordem de importância, os factores comuns de stress nos professores moçambicanos, brasileiros e moçambicanos do ensino básico e médio são: sobrecarga no trabalho, mau comportamento de alunos, maior número de alunos por turma e desinteresse, desmotivação dos alunos pela aprendizagem. Porém, os factores que tiveram maior pontuações em relação a média nos três países são: sobrecarga no trabalho, mau comportamento de alunos, seguido de salários baixos, condições inadequadas de trabalho. Resultados idênticos foram encontrados por Abacar (2015) numa amostra de professores do ensino básico público moçambicano e brasileiro. Nesse estudo, o autor revelou as seguintes fontes de stress dos professores nos dois países: salário, benefícios sociais, condições de trabalho, comportamento dos alunos, aprendizagem dos alunos, desvalorização da profissão docente, sobrecarga de trabalho, relações interpessoais, participação dos pais e encarregados de educação e desenvolvimento de carreira.

Estes resultados são consistentes com os encontrados em pesquisas realizadas noutros países. Kyriacou (1998); Kyriacou e Chien (2004), por exemplo, ao identificaram os alunos com atitudes negativas, falta de motivação de alunos em relação ao trabalho escolar, indisciplina dos alunos, mudanças rápidas nas exigências curriculares e organizacionais, condições de trabalho negativas, pressões de tempo e excesso de trabalho como preditores de stress nos professores. Por sua vez, Samad, Hashim, Moin e Abdullah (2010) revelaram que os factores de stress em professores malaios do ensino básico foram o mau comportamento dos alunos, tempo e a escassez de recursos, 0 trabalho em si, o relacionamento interpessoal, a falta de reconhecimento profissional e a carga de trabalho.

Os factores de stress encontrados neste estudo são frequentemente referenciados como causas de burnout entre professores do ensino médio e fundamental. Uma sistematização de notável importância realizada por Yong e Yue (2007) aponta cinco razões para a ocorrência do burnout do professor na China, que também são referenciados por diversos pesquisadores da área em diversos países: 1) Factores do aluno: a) problemas de indisciplina dos alunos, b) falta de motivação para os estudos e c) pressão em entrar no nível seguinte de educação; 2) Factores de trabalho: a) salários excessivamente baixos, b) falta de autoridade e status social e, c) classes numerosas; 3) Factores organizacionais da escola: a) tensas relações interpessoais, b) sobrecarga de trabalho e demais responsabilidades não educativas, c) falta de apoio e de reconhecimento da liderança e dos colegas, d) pressão de tempo, e) ineficácia das reformas educacionais, confusão e conflito de papéis, f) mau clima escolar e de classe, g) pressão dos supervisores e inspetores e, h) más condições de trabalho; 4) Factores pessoais: a) altas expectativas pessoais, b) incapacidade e c) exigências de trabalho; 5) Factores extraescolares: a) pressão da sociedade e dos pais e b) redução de pessoal.

Contudo, os resultados desta pesquisa mostram claramente que o trabalho docente precisa ser projectado ergonomicamente, em todos os níveis (Olaitan, 2009) especialmente no ensino básico e médio. Por esta razão, seria desejável desenvolver e aplicar um novo tipo de ergonomia que seja ergonomia educacional. Ergonomia educacional 
refere-se à aplicação de teorias, modelos, leis e métodos de ergonomia a contextos educacionais (Olaitan, 2004 apud Olaitan, 2009). Este autor mostrou em seu trabalho que as principais áreas de ergonomia educacional são: a) Ensino: métodos de ensino, auxílio ao ensino, motivação crescente dos alunos; b) Currículo académico: design, desenvolvimento, enriquecimento, avaliação; c) Avaliação de desempenho acadêmico: desenvolvimento de ferramentas de avaliação, avaliação de ferramentas de avaliação, testes de desempenho acadêmico, exames; d) Desenvolvimento de pessoal: alunos, professores, administradores; e) Concepção do design do contexto: lugar de estudo, concepção das salas de aula e salão polivalente, estações informáticas, ambiente físico e f) O quadro legislativo: leis e regulamentos.

\section{Considerações Finais}

Este estudo objectivou identificar as fontes de stress ocupacional em professores do ensino básico e médio em Moçambique, no Brasil e em Portugal. Com base nos resultados achados, diferentes factores stressores estão presentes no contexto de trabalho docente do ensino básico e médio nos três países, sendo a indisciplina e mau comportamento de alunos, a sobrecarga de trabalho, as remunerações baixas, o desinteresse dos alunos pela aprendizagem e desmotivação destes; as condições precárias e inadequadas de trabalho docente; o maior número de alunos/sala e o relacionamento com os pais e família dos alunos, os stressores comuns para os professores. Isso sugere a realização de ações pelos gestores escolares no sentido de reduzir ou minimizar as situações de stress, com vista a contribuir para o bem-estar dos professores e que os stressores identificados não se tornem agentes geradores da síndrome de burnout.

Enfim, a compreensão de factores de stress fornece perspectivas de prevenção e intervenção específicos para essa população (Genoud, Brodard, \& Reicherts, 2009). Nesse sentido, afigura-se importante o desenho de programas preventivos de modo a capacitar e treinar os professores na gestão de stress. E, também, os professores devem estar consciencializados na promoção de hábito de boas práticas de saúde. O conhecimento do stress ocupacional da docência também poderá despertar nos professores na elaboração de programas de prevenção a serem monitorizados pela autoridade da escola ou grupos de professores como forma de reduzir o stress entre os profissionais e promoção de uma vida mais saudável ao nível fisiológico e psicológico.

\section{Referências}

Abacar, M. (2011). Stress Ocupacional e o Bem-estar de Professores do Ensino Básico em Escolas Moçambicanas. Dissertação do Mestrado em Psicologia das Organizações, do Trabalho e Social. Faculdade de Ciências de Educação e Psicologia, Universidade do Porto, Porto.

Abacar, M. (2015). Burnout em Docentes do Ensino Básico em Escolas Moçambicanas e Brasileiras. Tese de Doutorado, Programa de Pós-graduação em Psicologia Cognitiva. Universidade Federal de Pernambuco, Recife.

Abacar, M., \& Aliante, G. (2016). Fontes de Stress Ocupacional em Professores Moçambicanos do Ensino Secundário Geral do 1 o Ciclo. Caso da Cidade de Nampula. Maputo, MINEDH.

Abacar, M., \& Amade, F. T. (2016). Trabalho, prazer e colapso do professor: Stress ocupacional e estratégias de gestão em profissionais do ensino primário público em Moçambique. Maputo, CEPE.

Bastos, J. A. Q. R. (2009). O mal-estar docente, o adoecimento e as condições de trabalho no exercício do magistério, no ensino fundamental de Betim. Belo Horizonte, 149f: il.

Benevides-Pereira, A. M. T., et al. (2003). Sintomas de stress em educadores Brasileiros. Aletheia, 17/18, 63-72.

Borba, B. M. R., et al. (2015). Síndrome de Burnout em professores: estudo comparativo entre o ensino público e privado. Psicol. Argum. jan./abr., 33(80), 270-281.

Branquinho, N. das G. S. (2010). Qualidade de Vida no Trabalho e vivências de bem-estar e mal- -estar em professores da Rede Pública de Unaí/MG. Dissertação de Mestrado apresentado no PPG em Psicologia Social, do Trabalho e das Organizações, Universidade de Brasília.

Capelo, M. R., \& Pocinho, M. (2009). Vulnerabilidade ao stress, estratégias de coping e autoeficácia em professores portugueses. Educação e Pesquisa, São Paulo, maio/ago, 35(2), 351-367. 
Carlotto, M. S., \& Palazzo, L. dos S. (2006). Síndrome de burnout e fatores associados: um estudo epidemiológico com professores. Cad. Saúde Pública. Rio de Janeiro, 22(5), 1017-1026.

Carvalho, A. D. F., \& Roazzi, A. (2011). Stress e burnout em professores. Teresina, EDUFPI. Comité de Conselheiros. 2003. Agenda 2025 - Visão e Estratégias da Nação. Maputo, EloGráfico.

Correia, T., Gomes, A. R., \& Moreira, S. (2010). Stresse Ocupacional em Professores do Ensino Básico: Um Estudo Sobre as Diferenças Pessoais e Profissionais. Actas do VII Simpósio Nacional de Investigação em Psicologia. Universidade do Minho, Portugal, 4 a 6 de Fevereiro, 1477-1493.

Costa, F. R. C. P., \& Rocha, R. (2013). Fatores estressores no contexto de trabalho docente. Revista Ciências Humanas UNITAU. Taubaté-SP - Brasil, Jan./jun., 6 (1), 18-43.

Cooper, C. L., Sloan, S. J., \& Willians, S. (1988). Occupacional stress indicator management guide. Great Britain, Thorbay Press.

Cruz, V. B. (2011). O Trabalho docente: do stress ocupacional ao burnout analisadas a partir do filme carregadoras de sonhos. Trabalho de conclusão de curso apresentado ao curso de Psicologia da Universidade São Francisco, como requisito parcial para obtenção do Título de Psicólogo. São Paulo.

Daft, R. L. (2005). Administração. São Paulo, Pioneira Thomson Learnin.

Diehl, L., \& Carlotto, M. S. (2014). Conhecimento de professores sobre a Síndrome de Burnout: Processo, fatores de risco e consequências. Psicologia em Estudo, 19(4), 741- 752.

Farber, B.A. (1984). A critical perspective on Burnout. In: B.A Farber (Ed.). Stress and Bunout in the human service profissions. New York: Pergamon Press.

Gasparini, S. M., Barreto, S. M. \& Assunção, A. A. (2005). O professor, as condições de trabalho e os efeitos sobre sua saúde. Educação e Pesquisa, São Paulo, maio/ago, 31(2), 189-199.

Genoud, P. A., Brodard, F., \& Reicherts, M. (2009). Facteurs de stress et burnout chez les enseignants de l'école primaire. Revue européenne de psychologie appliquée, (59), 37-45.

Gomes, A. R., Peixoto, A., Pacheco, R., \& Silva, M. (2012). Stress ocupacional e alteração do Estatuto da Carreira Docente português. Educação e Pesquisa, São Paulo, abr./jun, 38 (2), 357-371.

Gomes, A. R., Montenegro, N., Peixoto, A. M., \& Peixoto, A. R. B. C. (2010). Stress Ocupacional no ensino: um estudo com professores dos 3o ciclo e ensino secundário. Psicologia eSociedade, 22(3), 587-597.

Júnior, E. G., \& Lipp, M. E. N. (2008). Stress entre professoras do ensino fundamental de escolas públicas Estaduais. Psicologia em Estudo, Maringá, out./dez, 13(4), 847-857.

Kyriacou, C. (1998). Stress-busting for teachers. Cheltenham: Nelson Thornes.

Kyriacou, C. (2001). Teacher stress: Directions for future research. Educational Review, 53(1), 27-35.

Kyriacou, C., \& Chien, P. Y. (2004). Teacher stress in Taiwanese primary schools. Journal of Educational Enquiry, 5(2).

Koga, G. K.C, et al. (2015). Factores associados a piores níveis na Escala de Burnout em Professores de Educação Básica. Rio de Janeiro, Caderno Saúde Coletiva, 23(3), 268-275.

Ladeira, M. B. (1996). O processo do stress ocupacional e psicopatologia do trabalho. Revista em Administração. São Paulo, 31(1), 64-74.

Lowestein, L. (1991). Teacher stress learding to burnout: it's prevention and cure. Education Today, 41(2) 12-14.

Lima, F. (2004). Factores contribuintes para o afastamento dos professores dos seus postos de trabalho, actuantes em escolas públicas municipais localizadas na Região Sudeste. Dissertação apresentada na Universidade do Estado do Rio de Janeiro, Rio de Janeiro.

Lipp, M. E. N., et. al. (2002). O stress do professor. Campinas: Papirus.

Lipp, M. E. N., et al. (2004). O stress no Brasil: pesquisas avançadas. Papirus.

Lipp, M. E. N., \& Guevara, A. J. H. 1994). Validação empírica do inventário de sintomas de stress (ISS). Est. Psicol., 11(3), 43-9. 
Martins, M. das G. T. (2005). Sintomas de stress em professores das primeiras séries do ensino fundamental: Um estudo exploratório. Dissertação apresentada na Universidade Lusófona de Humanidades e Tecnologias, Lisboa.

Martins, M. das G. T. (2007). Sintomas de Stress em Professores Brasileiros. Revista Lusófona de Educação. (10), 109128.

Martins, M. da C. de A. s/d.. Factores de risco psicossociais para a saúde mental. Revista Educação, Ciência e Tecnologia, 255-268.

Marras, J. P., \& Veloso, H. V. (2012). Stress ocupacional. Rio de Janeiro, Elsevier.

Maslach, C., \& Leiter, M. P. (1999). Trabalho: fonte de prazer ou desgaste? Campinas, São Paulo, Papirus.

Maslach, C., Schaufeli, W. B., \& Leiter, M. P. (2001). Job burnout. Ann Rev Psychol. (52), 397-422.

Melo, B. T., Gomes, A. R., \& Cruz, J. F. A. (1997). Stress ocupacional em profissionais de saúde e do ensino. Psicologia: teoria e investigação, (2), 53-72.

Melo, W. F., et al. (2015). Síndrome de Burnout em Professores. REBES - ISSN 2358-2391 - (Pombal - PB, Brasil), OutDez., 5(4), 01-06.

Mesquita, A. A., Gomes, D. S., Lobato, J. L., Gondim, L., \& Souza, S. B. (2013). Stress e síndrome de burnout em professores: prevalência e causas. Psicol. Argum., Curitiba, out./dez, 31(75), 627-635.

Mokdad, M. (2005). Occupational stress among Algerian teachers. African Newslett on Occup. Health and Safety. (15), 46-47.

Monteiro, J. K., \& Dalagasperina, P. (2012). Preditores da síndrome de burnout em docentes do ensino privado. PsicoUSF, 19(2), 263-275.

Murta, S. G., \& Tróccoli, B. T. (2004). Avaliação de intervenção em Stress Ocupacional. Psicologia: Teoria e Pesquisa. Jan-Abr., 20(1), 39-47.

Naujorks, M. I. (2002). Stress e Inclusão: indicadores de stress em professores frente a inclusão de alunos com necessidades educacionais especiais. Cadernos de Educação Especial. Universidade Federal de Santa Maria. Centro de Educação/ Departamento de educação Especial/ Laboratório de Pesquisa e Documentação (Lapedoc), 1 (20).

Olaitan, O. L.. 2009. Prevalence of job stress among primary school teachers in South West, Nigeria. African Journal of Microbiology Research, 3 (8). Retrieved from http://www.academicjournals.org/ajmr

Oliveira, D. A. (2004). A reestruturação do trabalho docente: precarização e flexibilização. Educ. Soc., Campinas, Set./Dez., 25(89), 1127-1144.

Oliveira, V. B. C. de. (2003). Stresse ocupacional em amostra de professores do ensino médio da rede partícula da Educação. Dissertação apresentada na Universidade Católica Dom Bosco para obtenção do grau académico de Mestre em Psicologia. Campo Grande.

Pereira, E., Teixeira, C., Pelegrini, A., Meyer, C., Andrade, R., \& Lopes, A. (2014). Stress Relacionado ao Trabalho em Professores de Educação Básica. Cienc. Trab., Sep-Dic, 16(51), 206-210.

Reinhold, H. H. (2004). O sentido da vida: prevenção do stress e burnout do professor. Tese do Doutorado apresentada na Pontifícia Universidade Católica de Campus para obtenção do título de Doutora em Psicologia Profissão e Ciência. PUC-Campinas.

Ribeiro, T. A. (2015). Stress em Professores do ensino fundamental: estudo em uma escola social no sul do estado de Minas Gerais. Dissertação de Mestrado Acadêmico em Administração da Faculdade Novos Horizontes, Belo Horizonte.

Robbins, S. P. (2005). Fundamentos do Comportamento Organizacional. São Paulo, Pearson Prentice Hall.

. (2009). Fundamentos do Comportamento Organizacional. São Paulo, Pearson Prentice Hall.

Samad, N. I. A., Hashim, Z., Moin, S., \& Abdullah, H. (2010). Assessment of stress and its risk factors among primary school teachers in the Klang Valley, Malaysia. Global Journal of Health Science, October, 2(2), 163-171.

Santos, A. A. dos, \& Sobrinho, C. L. N. (2011). Revisão sistemática da prevalência da síndrome de Burnout em professores do ensino fundamental e médio. Revista Baiana de Saúde Pública, abr./ jun., 35(2) 299-319. 
Santos, D. A. S., Azevedo, C. A., Araújo, T. M., \& Soares, J. F. S. (2016). Reflexões sobre a saúde docente no contexto de mercantilização do ensino superior. Santa. Rev. Docência Ens. Sup., 6(1), 159-186.

Stachiw, R.T. da S., Ferreira, D. F., \& Batista, E. C. (2015). Níveis de stress em professores do ensino fundamental em uma escola pública de Rondônia.

Selye, H. (1956). The stress of life. Toronto: McGraw-Hill.

Servilha, E. A. M. (2005). Stress em Professores Universitários na área de fonoaudiologia. Rev. Ciênc. Méd., Campinas, jan./fev., 14(1), 43-52.

Silva, I. M. F. da. (2015). Questão social e Serviço Social no Brasil: fundamentos sócio-historicos, 2. ed. Campinas, São Paulo, EduFMT.

Silva, D. de P. da, \& Silva, M. de N. R. M. O. (2015). O Trabalhador com stress e intervenções para o cuidado em saúde. Trab. Educ. Saúde, Rio de Janeiro, 13 (1), 201-214.

Silveira, K. A., Enumo, S. R. F., \& Silveira, E. P. (2014). Indicadores de stress e estratégias de enfrentamento em professores de ensino multisseriado. Revista Quadrimestral da Associação Brasileira de Psicologia Escolar e Educacional. São Paulo, Set/Dez., 18(3), 457-465.

Weber, L. N. D., Leite, C. R., Stasiak, G. R., Santos, C. A. S., \& R. Forteski, R. (2015). O stress no trabalho do professor. Imagens da Educação, 5(3), 40-52.

Yong, Z., \& Yue, Y. (2007). Causes for burnout among secondary and elementary school teachers and preventive strategies. Chinese Education and Society, 40(5), 78-85.

Zille, L. P., \& Cremonezi, A. M. (2013). Stress no trabalho: estudo com professores da rede pública estadual de Minas Gerais. REUNA, Belo Horizonte, out-dez., 18(4), 111- 128.

\section{Sobre os Autores}

Gildo Aliante é bolsista do CNPq/PEC-PG. Mestrando em Psicologia Social e Institucional do Programa de Pós-graduação em Psicologia Social e Institucional do Instituto de Psicologia da Universidade Federal do Rio Grande do Sul-Brasil; Graduado em Planificação, Administração e Gestão da Educação, pela Universidade Pedagógica-Moçambique. Foi Docente do Departamento de Ciências de Educação e Psicologia na Universidade Pedagógica - Delegação de Nampula.

Mussa Abacar (PhD) é docente do Departamento de Ciências de Educação e Psicologia na Universidade Pedagógica, Delegação de NampulaMoçambique. Doutor em Psicologia Cognitiva pela Universidade Federal de Pernambuco-Brasil, Mestre em Psicologia das Organizações, Social e do Trabalho pela Universidade do Porto - Portugal, Licenciado em Psicopedagogia pela Universidade Pedagógica-Moçambique. 